\title{
Rising farm costs, marginal land cropping, and ecosystem service markets
}

\section{Ellen Esch}

University of Guelph

Kevin McCann

Universtiy of Guelph

Caroline Kamm

University of Guelph

\section{Bernal Arce}

University of Guelph

Oliver Carroll

University of Guelph

Aleksandra Dolezal

University of Guelph

Annalisa Mazzorato

University of Guelph

Dan Noble

University of Guelph

Evan Fraser

University of Guelph

John Fryxell

University of Guelph https://orcid.org/0000-0002-5278-8747

Bryan Gilvesy

ALUS Canada

Sam Krumholz

UC SanDiego

Malcolm Campbell

University of Guelph

Andrew Macdougall ( $\nabla$ asm@uoguelph.ca )

University of Guelph

Article 
Keywords: payment for ecosystem services, farm sustainability, industrialized agriculture, marginal land, land sparing, Canada, North America

Posted Date: February 15th, 2021

DOI: https://doi.org/10.21203/rs.3.rs-223049/v1

License: (c) (1) This work is licensed under a Creative Commons Attribution 4.0 International License. Read Full License 


\section{Abstract}

A growing challenge with industrialized agriculture is compensating farmers for devoting land towards producing ecosystem services, at a time when global food demands are accelerating. Here, we explore revenue thresholds that Payment for Ecosystem Service programs (PES) must approach to be competitive in present-day crop markets, amalgamating long-term North American data especially from Canada on input costs, crop yields, crop revenues after expenses, government subsidies, and land use. Two trends suggest that PES markets with stable revenues can be increasingly competitive, with inflationadjusted farm input costs now 50x higher than a century earlier and increasingly high revenue instability including net losses for some crops in some years. Since 1994, crop revenues in some regions have averaged $\$ 39$ acre $^{-1}$ US, peaking at $\$ 412$ but losing money $25.3 \%$ of time. Importantly, these data show how government subsidies have been a major stabilizing force, increasing revenues by $37.6 \%$ while reducing the frequency of losses by $50 \%$ - societal compensation to North American farmers is already the norm. PES programs could be most feasible on marginal lands, which are often targeted for retirement due to higher input requirements. However, trends in Canada reveal that marginal land cropping has increased by 5.2 million acres since 1990 and now constitutes $28.8 \%$ of all cropland. Our work reinforces how revenue instability simultaneously creates and constrains opportunities for PES markets, favoring market competitiveness because of shrinking crop revenues but pressuring farmers to expand production, including on marginal lands, as they struggle to offset revenue shortfalls while attempting to capitalize on growing global food demands.

\section{Introduction}

Feeding a growing world population while minimizing environmental impacts is a major challenge for industrialized agriculture ${ }^{1-5}$. Advancements including agrochemical inputs, mechanization, and crop breeding have increased global food production, which has risen $123 \%$ since 1970 alone ${ }^{6}$. At the same time, agricultural intensification is increasingly associated with environmental impacts including greenhouse gas emissions (GHG) and polluted drinking water, with impact costs estimated in the billions annually ${ }^{4,7}$. Given that global food demand is projected to be $\sim 50 \%$ greater by $2050^{8}$, agricultural systems must increase production in ways that are more environmentally sustainable ${ }^{1,9-12}$.

The prevailing global paradigms of industrialized agriculture - that inform the policies and economic models governing food production, distribution, and consumption - have largely prioritized increased yields, while struggling to manage environmental impacts. Inefficiencies in food production are well recognized, with solutions often emphasizing shifts in consumer diets and reduced supply chain waste $^{13,14}$. On-farm solutions towards increased efficiency include technological improvements ${ }^{10,15}$, redesign of production systems towards more diversified landscapes including areas with permanent cover $^{3}$, and enhanced nutrient management ${ }^{16,17}$. Still, with a few notable exceptions ${ }^{18}$, on-farm sustainability measures have not been widely implemented among agricultural producers. For instance, the long-standing land sparing hypothesis suggests that reductions in cropland (which "spares" land for 
other purposes) will occur when farmers adopt technologies that increase yields, which in turn reduce pricing because of over-supply such that the least profitable marginal lands are retired ${ }^{6,19,20}$. In other words, yield increases on the most productive land should serve as the driving force behind the retirement of marginal lands. However, in many cases the opposite has happened ${ }^{6,21}$, with farmed land increasing by $21 \%$ globally since the 1970 's despite yield increases, extensive land retirement programs in some countries, and often declining commodity prices ${ }^{5,22,23}$. Synthetic fertilizer and pesticide application have also increased despite evidence of biophysical yield thresholds in response to factors including drought $^{10,23-25}$, linkages with ground water pollution $4,26,27$ and biodiversity declines ${ }^{28,29}$.

A core challenge for industrialized agriculture is finding ways to simultaneously increase production, reduce adverse environmental impacts, and maintain economic viability 5,30 . Payment for ecosystem services (PES) programs attempt to reconcile these factors via economic incentives (e.g., payments to farmers for carbon storage, pollination, and nutrient retention ${ }^{30,31}$ ), and often include targeting the retirement of marginal cropland where input demands are higher relative to production ${ }^{32}$. Ecosystem service pricing for farms has been estimated using various methods, but one persistent challenge is determining how these values align with crop profits, where the former ideally approaches or exceeds the latter $^{33}$. The issue is complex. On one hand, substantial savings are generated to farmers by converting marginal lands to permanent cover, simply by the cessation of high-cost inputs required to produce crops on poor soils. On the other, services typically do not generate consistent revenue under current market conditions and, given rising food demands globally, cannot be produced at the expense of food production. As such, PES-based schemes for agriculture must navigate the same factors as commodity crops in terms of input costs, market prices, and after-cost revenues ${ }^{33}$, while being integrated into farms without sacrificing production. It is a substantial challenge ${ }^{34}$.

We explore century-long trajectories of farm revenue in industrialized agriculture especially in Canada, thereby clarifying the monetary thresholds needed for PES programs to become an economically viable revenue option for farmers. The valuation of farm-derived PES commodities such as soil carbon and nutrient retention has been extensively discussed ${ }^{30}$ but it remains difficult to reliably determine, especially when used as a basis to create dependable revenue streams. Carbon storage benefits to society, for example, have been estimated $>\$ 400$ US acre ${ }^{-1}$ within permanent-cover grassland ${ }^{35}$ yet we know of no example where such amounts are consistently paid to the producer. We take a different approach, focusing instead on the economic conditions that currently exist for crop producers, which we use as a basis to determine a competitive value for PES commodities. We do so by analyzing trends of crop input costs, yields, and after-cost revenues that, in turn, inform the economic levels that PES programs must attain serve as a competitive revenue stream. Analyses on agricultural productivity have a long legacy, including debates on whether trends in food production (tonnes per unit time) and profitability are increasing and the mechanisms that determine these increases including the amount of land being farmed, yield efficiency (tonnes per unit area), chemical inputs, government subsidies, and labor $5,23,31,33,36,37$. For our analysis, we utilize unique long-term Canadian farm data relating to crop 
input costs, crop production and yield, commodity market pricing, after-cost revenues, and land use. Using time series analyses, we examine transitions in agricultural input costs, especially fertilizers and pesticides that now constitute the largest percentage of total farm expenses (Table S1) and are associated with environmental impacts (e.g., $\mathrm{N}_{2} \mathrm{O}$ emissions from fertilizers). We examine land use trends relating to marginal lands, including whether marginal land use is declining as predicted by land sparing hypotheses ${ }^{6}$. Finally, we examine after-cost revenue trends since the 1990s from two regions of North America that help describe the market conditions within which farm-based PES programs must operate.

We focus our analyses on industrialized farming mostly in Canada, which possesses an unprecedented database on 20th and early 21 st century agricultural trends. These data, starting in 1926, span the entirety of modern agriculture's shift to intensification including the beginnings of industrial-scale manufacture of nitrogen fertilizer and mechanized farm equipment, the Dustbowl (1930s), Green Revolution (mid-20th century), the accelerating globalization of farm commodity markets starting especially in the 1970s, widespread farm declines of the 1980s, and the ethanol boom (early 2000s). We expand our analysis to include specific regions within the United States and Canada with available data, to broaden analysis on issues such as labor, government subsidies, transportation, and land rental which are lacking in the long-term dataset (Fig. S1; see also Table S1). We also include longer-term data from the United States Department of Agriculture (USDA) from 1948-2017. The latter shows similar trends of rising input costs as the Canadian data, albeit over a shorter time periods and reflecting differences in scale as the US has $\sim 10$ times more farms and crop acreage, and has more widely implemented land retirement programs (e.g., the US Conservation Reserve Program [CRP]).

\section{Results And Discussion}

Our first analysis presents several interacting trends in the agricultural sector over the last century, which suggest increasing opportunities for economically competitive PES markets with interannually stable price returns. Canadian data from 1926-2018 illustrate a significantly widening gap between inflationadjusted management input costs, now 50 times higher than 1926, versus crop production at only 2.7 times higher despite significant advancements in management and mechanization. Simultaneously, the land base for cropping has increased 1.7 times while inflation-adjusted market prices have declined -0.4 times (Fig. 1A). Time series analyses show how steadily increasing input costs over the last century are rising at a much faster rate than other factors (see Supplemental Methods). These trends in input costs, crop production, and pricing have been previously reported for industrialized farming for various periods of the late 20th century in North America and abroad ${ }^{32}$ - our data show it as a steadily increasing trend for the entire duration of modern industrialized farming in Canada.

Our data help illustrate the many component factors that interact to determine agricultural productivity in Canada. For example, it can be seen how the century-long increases in production derive largely from the near-doubling of farmland and the tripling of yield defined as the amount of crop produced per unit area (Fig. S2). Similar long-term increases in yield are reported from the US, with fewer farms producing more food in association with the various technological advances of industrialized agriculture including 
chemical inputs, crop breeding, and mechanization ${ }^{36}$. Simultaneously, however, production increases struggle to maintain revenues against steadily declining and often volatile market price. Market price for major grain crops in Canada, adjusted to 2018 SUS, started at $\$ 466$ tonne $^{-1}$ in 1926, peaked in the 1970s at $\$ 765$ tonne $^{-1}$, rose again between 2000-2010 in line with global market trends relating to ethanol, but has since averaged $\$ 252$ tonne $^{-1}$. There are other influential components which we could not assess due to data limitations (i.e., not available to 1926), but also play a significant role in tightening profit margins in industrialized farming in North America generally. For this we rely on US data. There have been large savings on labor created by mechanization, such that labor costs for the nine major grain crops that we target now constitute 3\% of annual farm expenditures (Table S1, Fig. S1). However, a range of direct and overhead expenses have emerged or intensified over the last century that now overwhelm these labor savings, including transportation, depreciation of farm equipment and buildings, crop insurance and land rental (Table S1). Data from the USDA for 1947-2017 show that input costs for fertilizer, pesticides, and seed alone began to exceed labor costs in the early 1980s, and this gap has widened significantly since (Fig. S3). These USDA data include labor-intensive fruits, nuts, and vegetables, whose labor costs range between $25-30 \%$ of all expenditures. For the nine major grain crops of our analysis (corn, soy, wheat, canola, barley, flaxseed, oats, peas (dry), and rye), the labor costs are much lower $(\sim 3 \%)$ because many tasks are done mechanically (Table S1).

The Canadian trends in inputs and production over the last century (Fig. 1A) are representative of most regions globally, even when analyzing a smaller subset of years (since 1961) and inputs (only massbased fertilizer inputs; Fig. S4). In other words, while improvements in technology and increased land clearance have contributed to substantially higher yield-driven increases agricultural productivity in many parts of the planet ${ }^{23}$, farming has nonetheless become less profitable per acre with the ratio of cost to production steadily widening. This latter trend is consistent with the "treadmill" effect of agricultural input applications, whereby input-dependent cropping systems can experience diminishing economic returns over time even as chemical applications increase ${ }^{38-40}$. As we will discuss, this trend also coincides with an increasing reliance on marginal-land farming, which is ironic given that the biophysical limitations of marginal land often create above-average cost:production ratios.

Many of these Canadian trends in input costs, crop yields, and market pricing intensified starting the early 1970s (Fig. 1B). This period coincides with accelerating shifts in factors that still affect farm economies globally, including a significant rise in grain consumption by livestock, the emergence of soybean as a major grain commodity, the expanding scope and extent of global markets with associated trade deals including attempted tariff reductions (e.g., 1972 US-USSR grain agreement, the GATT Tokyo Round negotiations), rising energy prices, and the privatization of agricultural credit and insurance markets ${ }^{41}$. One symptom of these shifts is an intensified decline in the efficiency of input costs versus production, especially once costs exceeded $1.2 \pm 0.16$ billion dollars per year (estimate $\pm 1 \mathrm{SE}$ ) (Fig. 1B). This widening gap between costs and production has been previously reported for the mid- $20^{\text {th }}{ }^{-}$century 42,43 concerning total energy inputs and more recently with nitrogen use efficiency ${ }^{1}$. Our work shows that this trend persists (Fig. 1B). 
There have been long-standing predictions that farm revenues and crop production would tightly connect with the amount of land being farmed, with over-supply of commodities suppressing both crop prices and land use (i.e., land sparing ${ }^{6}$ ). Marginal land use should be especially curtailed under such scenarios, due to the inherent inefficiency of higher input costs and lower yields on such land. However, our results clearly show the opposite outcome for Canada (Fig. 2A), in line with reports from elsewhere including the United States in recent years $5,22,44$. We do observe rising production and falling prices, but these trends are associated with more land use, not less (Fig. 1A). The reasons behind these trends appear to be straight-forward: when confronted with low crop profits for a given commodity, farmers tend not to spare land but look to increase revenues by planting more land ${ }^{5,38}$, shifting to other more valuable crops based on current markets, and/or increasing the quantity of inputs linked to higher yields (fertilizers, pesticides, seed technologies) with associated higher costs. This latter factor of higher cost may be especially influential in preventing land sparing, and indeed may represent a significant deterrent to the formation of PES markets. If production costs remain constant, then declining market price with oversupply should theoretically create conditions where land is spared ("sparing" Fig. 3). However, rising costs appear to disrupt this balance, such that farmers are often driven to grow crops on more land $5,22,44$ to remain competitive as their revenues decline ("rising costs and consumption" Fig. 3).

Not only has crop land expanded in recent decades in Canada, but an increasing proportion of this land is classified as marginal (Fig. 2). Marginal lands are defined as being severely limited by texture, drainage, fertility, slope or climate (Table S2) ${ }^{45,46}$. Cumulatively, the cropping of marginal land (soil classes IV-VII) increased in Canada by 2.1 million hectares (5.2 million acres) between 1990-2010. Meanwhile cropland on the most fertile agricultural land (class I) declined by 0.11 million hectares (Fig. 2A) mostly due to urban expansion, which a trend occurring globally (Fig. S5). Loss of arable land to settlement further pushes crop production into less fertile areas ${ }^{47}$. New cropland most often appears to arise by cultivating grasslands, which can include previously retired land (Fig S5) ${ }^{22,44}$. Combined with overall net growth in cropland since 1926 (Fig. 1A), these land use trends leave modern agriculture relying more heavily on marginal lands. It also corroborates the trend towards fertile lands being increasingly scarce ("peak land") ${ }^{48}$. As a result, today nearly one-third of crop production in Canada (28.8\%) occurs on marginal lands while only $7.3 \%$ of cropland occurs on the highest quality agricultural land (class I) (Fig. 2B). Globally, approximately $17.1 \%$ of crop land occurs on areas deemed to have marginal or unsuitable soils $^{8}$, driven by a range of economic, social, and political factors ${ }^{49}$. The long-term disadvantages of market prices driving marginal land cultivation are well established - market instability can drive expansion onto these areas ${ }^{50}$ with benefits that are not sustainable, given the above-average input costs, greater frequency of production shortfalls (e.g., increased risk of crop loss to drought), with environmental impacts such as biodiversity loss that are not easily reversed if and when commodity prices decline and the land is abandoned ${ }^{22,51-53}$.

Finally, farm intensification is increasingly associated with a range of environmental impacts, driving calls for greater attention to sustainability measures including the increased production of ecosystem services. For GHG, farming in Canada produces $8 \%$ of annual emissions (2nd overall), including $31 \%$ of 
the national total for methane and $76 \%$ for $\mathrm{N}_{2} \mathrm{O}^{54}$. Globally, farming produces an estimated $15-25 \%$ of all anthropogenic $\mathrm{GHG}$ output ${ }^{23}$. Although the numbers of PES programs are rapidly expanding globally ${ }^{33,55}$ widespread implementation in industrialized farming remains a challenge, given the scarcity of dependable revenue streams available to farmers. Indeed, as our analyses shows, the current economic climate in agri-food production is favoring more intensification rather than less, despite some notable exceptions including the U.S. Department of Agriculture's Environmental Quality Incentives Program and, in Europe, the second pillar of the E.U. Common Agricultural Policy. This trend of intensification has direct scalable impacts on how farming can affect the environment - the steady rise in fertilization and pesticide application in recent decades shows no signs of abating (Figs. 1, S1, S6). Further, ongoing intensification simultaneously increases the importance of PES-based environmental sustainability measures on farm landscapes, while potentially limiting their effectiveness globally given that panregional implementation may be needed when service gains per unit area are modest (e.g., short-term carbon storage in soils ${ }^{56,57}$ ). Thus, one challenge is finding a balance between the parallel development of PES commodities and intensification of crop production, such that the negative environmental impacts of the latter do not outweigh the benefits of the former.

Although farm intensification challenges the creation of PES markets, it can create opportunities deriving from rising farm input costs and associated revenue instability. Recent trends in after-cost revenues from major crops in the central United States show narrowing gains and high interannual volatility (Fig. 4, Table S1). Crop farmers in central and western US reported record low totals in net farm revenue for 2019, with the last five years falling within the bottom third of income totals reported historically ${ }^{58}$. In this context, PES revenue streams could provide valuable income supplementation (Table S1), especially if these revenues have lower interannual price volatility. For example, revenues for the nine major grain crops of the US since 1994 averaged $\$ 53.9$ acre $^{-1}(+-\$ 9)$, but this includes unpredictable fluctuations in individual crop price with net loss in some years (Fig. 4, Table S1). An important feature of these pricing trends is the role of government support payments in reducing revenue volatility - in the absence of such support, average revenue per crop drops from $\$ 53.9$ to $\$ 39.2$ US acre ${ }^{-1}$ (+- \$9) with one or more crops reporting net revenue losses $25.3 \%$ of the time (Fig. 4). A persistent challenge with PES programs is establishing revenue sources, with government-based payments often touted as the most attainable and in some cases preferred short-term solution ${ }^{59}$. Our farm data clearly show that government contributions are already the norm with food production in North America. Indeed, 2019 pre-COVID farm subsidy totals in the United States and Canada were approximately $\$ 16$ billion USD and $\$ 1.5$ billion USD respectively 60,61 . Government support for food production is one of the more long-standing challenges in global trade, especially domestic payments that are considered to "distort" production volume or price. Less contentious are "decoupled" income supports including two factors critical for PES: stabilization of farm income and support for environmental programs ${ }^{62}$. The US CRP, for example, provided inflation-adjusted average annual rental payments of $\$ 77$ acre $^{-1}$ county $^{-1}$ in 2020, well within the net profit margins for most major crops between 1994 and 2017 (Fig. 4). Globally, PES revenues can come in a range of forms including regulatory measures, initiatives within food supply-chains, and cap-and-trade programs for GHG 
smmissions $31-33,55,57$. Again, however, the wide-spread availability and long-term dependability of these programs for industrialized farmers, in the form of functioning markets with liquidity, remains a challenge.

In total, the environmental sustainability of farm landscapes is impeded by increasing food demands globally, a widening gap between farm costs and market prices, and expanding dependance on marginal lands despite numerous retirement programs. Recent trends in the US CRP program illustrates these challenges, having retired 31 million acres of mostly marginal land at its peak in 2007 but with $25 \%$ now converted back to cropland including $~ 900,000$ acres of formerly restored permanent cover grassland ${ }^{44}$. Similarly, an analysis from 2008-2016 showed cropland expansion in the United States averaging 1 million acres per year, with $\sim 70 \%$ of those lands appearing to be marginal given that their production totals fell below the national average ${ }^{22}$. Our work emphasizes the various long-term trends in industrialized farming in North America, highlighting the shifting trajectories of farm costs, after-cost revenues, crop yields, and land use. There have been numerous calls for the redesign of industrialized agriculture, to increase efficiency in food production while reducing environmental impacts ${ }^{1,3}$. Clearly this redesign must include more accurate demand-based valuation of environmental impact costs and the benefits of "growing" services on farms, with market creation funded though policy, direct tie-ins with consumer food prices, or both. Sustainable agriculture must additionally make logistical and financial sense for farming operations of all sizes, including when societal or economic forces create food demands that increase the pressure to cultivate marginal lands ${ }^{63}$. To date, the environmental costs of modern agriculture on factors such as water quality often go unpaid leading to growing threats to human health and biodiversity $4,16,17,26,64,65$. Indeed, five of the top eleven economic risks identified for the next decade by the World Economic Forum ${ }^{66}$ are environmental, with 'biodiversity loss and ecosystem collapse' and 'human-made environmental disaster' increasingly connected to farming given the agriculture's large global footprint including GHG emissions and intensifying chemical inputs ${ }^{4,26,27}$. There seems an increasingly urgent need, at a societal level, to begin more fully paying these farm-based costs. Our work suggests that if marginal land-based PES programs are made viable in economic terms, they may contribute to achieving these goals. We recognize that if such programs can offset revenue shortfalls, they may serve a dual role in meeting environmental objectives while bolstering revenues so that producers may continue to meet growing global food demands.

\section{Methods}

All data used are publicly available (Table S3). There are many disparate sources of agricultural data, which can be difficult to amalgamate due to differences in duration and units of measure. There can also be wide differences in the calculation of agricultural indices especially relating to total farm output, total factor productivity, and total farm inputs (e.g., USDA vs Statistics Canada) and the scale at which they are calculated (e.g., national versus regional). These differences in data have long challenged the comparative assessment of the magnitude and long-term direction of farm revenues in North America and globally. Here, we rely on unmodified raw data from the Canada and the United States, forgoing 
indices in favor of the underlying data used to calculate them. These data allowed comparisons among core driving factors affecting after-cost revenues for farmers, including comparisons in long term input trends in Canada (Fig. 1) versus the US (Fig. S1), price variability and government subsidy (Fig. 4, Table S1), changes in yield efficiency defined as the amount of crop produced per unit area (Fig. S2), the longterm relationship between labor saving versus crop input costs in the US (Fig. S3), and how North America trends compare broadly to global trends (Fig. S4). We also examined land trends by soil class in farming, including marginal lands (Classes IV-VII), although we were unable to conduct explicit analyses on crop yields and after-cost crop revenues by soil class over time - these data do not exist nationally in Canada or the US in part because yield declines are masked by farm husbandry (i.e., farmers can maintain yield on marginal lands by increasing inputs).

Given data variability relating to agriculture, our analyses primarily capitalize on the scope and extent of the long-term Canadian farm data, while also drawing upon similarly comprehensive data from other Canadian and US sources albeit over shorter durations and narrower spatial resolutions (Table S1, Table S3). We view trends in farm revenues between the Canada and US to follow broadly similar trajectories, given their significant overlap with respect to the long-term evolution of modern industrialized farming access to the same technological developments, land use patterns, trajectories of population change, and pricing systems (Figs. 1A, S1). On the other hand, we do not merge data sources given that the Canadian and US agricultural systems have some unique political (e.g., farm-support programs, conservation practices) and geographic contexts (e.g., the suite of field crops grown and climatic conditions), including a trade partnership that has occasionally seen regulatory shifts with time (e.g., Smoot-Hawley Tariff Act of 1930). As such, we conduct a series of complementary but discrete analyses specific to each data source, clearly delineating the source of the data, the variables involved, the time period, and comparability where relevant.

For our analyses comparing agricultural input costs and total crop production (MT) for major field crops across Canada, we used data reported by Statistics Canada over the past century starting in 1926 (Table S3). For Fig. 1, we used weight-based metrics of field crop production (MT) as the "output" term with "inputs" given as the sum of inflation-adjusted dollars spent on three categories (fertilizer and lime, pesticides, and commercial seed). Dollar-based estimates of input costs correlate strongly with massbased consumption and provide coverage of otherwise incomplete mass-based data (Fig. S6). Costs in other areas such as labor and transportation also contribute to production (e.g., Table S1), but these data are absent from the Statistics Canada data- we use other more recent data sources from Canada and the United States to fill these gaps (Table S3).

For comparable analyses of US farm input cost including factors such as labor and chemical use (Fig. S1), we draw upon USDA farm data from 1948-2017 (https://www.ers.usda.gov/dataproducts/agricultural-productivity-in-the-us/agricultural-productivity-in-the-us/). These data cover a shorter time period than the Canada data yet mostly show similar trends in input. They also contain detailed information of trends in labor costs and overall land use not available in the Canadian data, which have been variously used by the USDA as part of a broader calculation of indices such as total 
factor productivity. As stated, we forgo the use of these indices, instead using the source data to target specific trends including changes in total labor costs and, relatedly, changes in labor associated with mechanization relative to non-labor costs (Fig. S3). One notable long-term difference between Canada and the US is total land use for cropping - net trends have generally been declining in the US (Fig. S1) but increasing in Canada (Fig. 1). A key factor in these trends is scale, given that the US has 10 times more cropped land in Canada with peak land retirement associated with the US CRP at 31 million acres comparable to $1 / 3$ of the entire land base of cropping in Canada. As well, trends in land use have been shifting in the US in recent years, with expansion of crop lands back onto formerly retired lands in response to global market demands ${ }^{22,44}$.

\section{Long-term Trends in Crop Inputs - Canada (Fig. 1)}

Dollars spent on three categories were chosen to represent the cost of agricultural intensification: 1) fertilizer and lime, 2) pesticides, 3) commercial seed. All values used in this analysis are costs before rebates to reflect the true dollar cost of intensification. These costs associated with farm operation were converted into 2018 Canadian dollars (CAD) by using the annual consumer price index (CPI) and Eq. (1):

Equivalent $2018 C A D=$ Cost $_{X}{ }^{C P I_{2018} / C P I_{X}(1)}$

where Cost $_{x}$ and $\mathrm{CPI}_{\mathrm{x}}$ represent the $\mathrm{CPI}$ and the annual value of inputs purchased in year $\mathrm{X}$. An annual $\mathrm{CPI}$ for all items was used rather than a specific farm input price index to facilitate comparison between costs and profits. The 2018 CAD values were subsequently multiplied by the average 2018 USD-CAD exchange rate of 1.297 (https://www.irs.gov/individuals/international-taxpayers/yearly-average-currency-exchangerates) to convert values to the 2018 USD reported throughout the paper. In summary, we adjusted for inflation within Canada first, and then converted those values into 2018 USD. We did not convert CAD annual metrics into USD annual metrics because currency exchange rates are only available since 1970 (https://www.ers.usda.gov/data-products/agricultural-exchange-rate-data-set/agricultural-exchange-ratedata-set).

We preferred dollar-based estimates of input costs due to the lack of comprehensive and long-term data on weight-based amounts. We note that the inflation-adjusted value spent on fertilizer and lime (before rebates) correlates strongly with mass-based amount of fertilizer consumed by Canadian agricultural markets between the years 1967-2018 (Fig. S6). We recognize that nutrients derived from manure applications are globally important, but we lack sufficient data to analyze their contribution and costbasis to fertilizer inputs presented here.

\section{Long-term Total Crop Production (Metric Tonnes [MT]) - Canada}

Most of our analyses target nine grain crop species of North America (e.g., Fig. 4), which represent a large percentage of the market (especially since the 1970s, given increase usage of soybean and canola) and has the best contemporary data. For our longer-term analyses of inputs and production from Canada however (Fig. 1A), we draw upon a wider number of crops, in part because many were formerly more widely planted especially in the early to mid-1900s. As such, acres seeded and total production were used 
as agricultural outputs for 27 major field crops: barley, beans (dry, white and colored), borage seed, buckwheat, canary seed, canola, caraway seed, chick peas, coriander seed, corn (for grain and silage), faba beans, flaxseed, hemp, lentils, mixed grains, mustard seed, oats, peas (dry), rye, safflower, soybeans, sugar beets, sunflower seed, tame hay, triticale, wheat. We used area seeded, rather than area harvested, for consistency and to maximize the time span of the data (area harvested started in 1965, while area seeded was available even prior to 1926 [since 1908]).

Farm market prices (i.e., mass-weighted prices paid to farmers, as opposed to after-cost revenues which are calculated by subtracting total-farm cost from market price - see Table S1), averaged by year for all crops, were all modified to show inflation-adjusted dollars using Eq. 1, and subsequently converted to 2018 USD. Long-term (> 50 years of data) farm market prices were only available for a subset of the major field crops (9 species: barley, canola, corn (for grain), flaxseed, oats, peas (dry), rye, soybeans, wheat). In instances where a commodity purchasing board offered subsidies (i.e., Canadian Wheat board payments) we used market prices before payments. In instances where multiple grades (i.e., wheat for milling versus other purposes), species (i.e., durum and common wheat, Triticum turgidum and $T$. aestivum, respectively), or geographic distributions in Canada (i.e. Ontario versus Alberta) had different market prices, we took the average price for each year.

\section{Long-term Land Use Change - Canada}

Changes in land use were compiled using an online tool from Agriculture and Agri-Food Canada (www.agr.gc.ca/atlas/landu), which shows changes between the years 1990, 2000, and 2010 for all areas of Canada south of $60^{\circ} \mathrm{N}$ at a pixel resolution of $30 \times 30 \mathrm{~m}$. Land cover categories were aggregated into 7 main categories. "Forest" consisted of land under "forest," and "forest wetland" cover. "Grassland" consisted of "grassland managed" and "grassland unmanaged." "Trees" consisted of "trees" and "treed wetland." "Wetland" consisted of "wetland," "wetland shrub", and "wetland herb." "Roads," "settlement," "unclassified," and "other land" categories remained unchanged. In some instances, land use change is reported twice. For instance, areas that were converted from grasslands into cropland, and subsequently into settlement land cover, would be reported as both land change into cropland, and also land change out of cropland (see Fig. S5).

Land use change was spatially linked to soil fertility using the Canada Land Inventory (CLI) rating for soil. CLI ratings range from soil class I - VII and indicate the suitability of land for agriculture based on climate and soil characteristics (Table S2). The soil survey was completed between 1929 and 2002 without a uniform map scale, and in some cases, land area was classified as belonging to multiple CLI ratings. In these cases, the land class with the largest percent cover was selected for the entire spatial extent. Agricultural land cover at a $30 \times 30 \mathrm{~m}$ scale released by Agriculture and Agri-food Canada from 2016 was overlaid upon soil fertility information, and crop area overlapping with soil fertility gradients was calculated. Not all agricultural land overlaps with a soil fertility gradient, though this is only true for $1.7 \%$ of Canada's agricultural land. As stated above, one analysis we could not do was testing relationships among inputs, yield, and land quality, with the assumption that farmers stabilize yield on poorer lands by adding more inputs (fertilizer, irrigation). Poorer lands may also show more inter-annual 
yield fluctuations with drought. These data are generally lacking globally. They are also difficult to obtain remotely (e.g., Satellite-derived NDVI, to estimate productivity) in part because farm management uses inputs to overcome land limitations. As such broad qualitative definitions of marginal land agriculture (e.g., Classes I-VII - Table S2) have not widely been linked to quantitative yield declines in the absence of management interventions. However, they can be used to provide an important starting point for considering geographically explicit suitability for crop production, which is our focus.

\section{After-cost Revenues - central and western United States, central Canada}

For after-cost farm revenues, we leverage two regional data bases with the full slate of costs and income by crop. Regional assessments of total farm productivity tend to be more informative than national-level assessments, given the latter tends to integrate, and sometimes mask, often widely disparate regional trends in crop identity, climate impacts on annual yield, labor trends, and local market conditions. The first set of data comes from farms of central and western United States as reported by FINBIN for 19942018 for nine major crop species (corn, soybean, wheat, canola, barley, flaxseed, oats, peas (dry), and rye). FINBIN is one of the largest farm financial databases in a collaboration between the Center for Farm Financial Management at the University of Minnesota and the National Institute of Food and Agriculture at the United States Department of Agriculture ${ }^{53}$ (Table S1). These data contain the full ledger of farm costs (both direct and overhead), outputs (crop production and yield per unit area), government subsidy, and market price, allowing us a full assessment of "total factor" farm revenue on these farms (e.g., versus "single factor" revenue based only on, for example, market price per acre or per bushel whose value alone is important but hides the various input costs such as machine costs, labor, and fertilizer required to achieve it).

We also leverage a similar database for after-cost revenue from the province of Ontario in Canada, which estimates field crop budgets for farmers ( http://www.omafra.gov.on.ca/english/busdev/facts/pub60.pdf ). These data are largely identical to FINBIN in describing the full ledger of input costs including labor, although they can underestimate cost in that land rental and pesticide costs for some crops are excluded. Given that $53 \%$ of farmland in Ontario is rented, at an average costs of $\$ 180$ acre $^{-1}$ ( https://www.farms.com/ag-industry-news/ontario-s-farmland-values-and-rental-rates-679.aspx ), we extrapolated land rental costs based on these values (Table S1B). For pesticide costs, we substituted FINBIN values for corn and soybean. Pesticide costs were not included in the province of Ontario data, even though insecticides and fungicides are often used. In 2018 for example, wet conditions triggered an outbreak of Gibberella Ear Rot, a toxic fungal pathogen affecting feed corn for cattle. This outbreak required significant treatment by farmers, and even more substantial government assistance ( https://ipolitics.ca/2018/11/09/ontario-farmers-facing-catastrophic-disease-outbreak-in-feed-corn/ ). Again, the province of Ontario does not include pesticides in their estimation of after-cost revenues, but we are assuming that the FINBIN values are reasonable approximations.

\section{Global trends (Fig. S4)}

Data from FAOSTAT were compiled since 1961 (obtained from http://www.fao.org/faostat/en/\#data). At the global level, mass-based fertilizer inputs (nitrogenous, phosphate, and potash fertilizers) were 
aggregated since 1961 for the five main regions of the world. Fertilizer data from the year 2002 were excluded within the archived dataset because it is reported within the current dataset. Pesticide, irrigation, and seed costs were not available for the full timespan, and hence excluded. Crops outputs (production) were filtered to only include those belonging to either cereals or oilcrops per FAO definition. Other types of crops were excluded due to poor continuity or not being representative of agricultural practices highlighted by this analysis (for instance tree crops). Crop market prices were available since 1991, and market prices from Venezuela in 2016 (inflation) and melon-seed prices from Mexico in all years (unrealistically high) were excluded.

We recognize shifts in geopolitical ontogeny between 1961 and 2016 (for instance the former U.S.S.R. is reported within Europe, however subsequent countries formed after the breakup of the U.S.S.R. belong to either Europe or Asia), however we chose to use FAO's aggregated data at the continent-level to be consistent with other studies using FAO data.

\section{Statistical Methods}

All data were processed on R 3.5.1. Packages tidyverse (version 1.2.1), cowplot (version 0.8.0), readxI (version 1.0.0), gridExtra (version 2.3), scales (version 0.5.0), and lubridate (version 1.7.4) were used in the analyses.

\section{Declarations}

\section{Acknowledgments}

We thank Teresa Lewitzky from the University of Guelph's Data Resource Center for assistance with geospatial data. Funding for this project was provided by the Canada First Research Excellence Fund under the Food from Thought grant to the University of Guelph.

\section{Competing Interests:}

The authors declare no competing interests.

\section{Materials \& Correspondence}

Should be directed to EHE and ASM.

\section{Author contributions:}

All authors contributed to the discussion, conceptualization, and revisions of the manuscript. E.H.E., A.S.M., and K.S.M performed data analysis. E.H.E. and A.S.M. wrote the first draft, with all other authors contributing writing on later stages. 


\section{References}

1 Foley, J. A. et al. Solutions for a cultivated planet. Nature 478, 337-342, doi:10.1038/nature10452 (2011).

2 Garibaldi, L. A. et al. Farming approaches for greater biodiversity, livelihoods, and food security. Trends Ecol Evo/32, 68-80, doi:10.1016/j.tree.2016.10.001 (2017).

3 Pretty, J. Intensification for redesigned and sustainable agricultural systems. Science $\mathbf{3 6 2}$, eaav0294, doi:10.1126/science.aav0294 (2018).

4 Springmann, M. et al. Options for keeping the food system within environmental limits. Nature 562, 519-525, doi:10.1038/s41586-018-0594-0 (2018).

5 Fuglie, K. O., Wang, S. L. \& Ball, V. E. Productivity growth in agriculture: an international perspective. (CABI, 2012).

6 Rudel, T. K. et al. Agricultural intensification and changes in cultivated areas, 1970-2005. P Natl Acad Sci USA 106, 20675-20680, doi:10.1073/pnas.0812540106 (2009).

7 Zhang, W., Ricketts, T. H., Kremen, C., Carney, K. \& Swinton, S. M. Ecosystem services and disservices to agriculture. Ecol Econ 64, 253-260, doi:10.1016/j.ecolecon.2007.02.024 (2007).

8 Alexandratos, N. \& Bruinsma, J. World agriculture towards 2030/2050: the 2012 revision. (12-03, Agricultural Development Economics Division, Food and Agriculture Organization of the United Nations, 2012).

9 Tilman, D., Balzer, C., Hill, J. \& Befort, B. L. Global food demand and the sustainable intensification of agriculture. P Natl Acad Sci USA 108, 20260-20264, doi:10.1073/pnas.1116437108 (2011).

10 Cassman, K. G. Ecological intensification of cereal production systems: yield potential, soil quality, and precision agriculture. P Natl Acad Sci USA 96, 5952-5959, doi:10.1073/pnas.96.11.5952 (1999).

11 Matson, P. A., Parton, W. J., Power, A. G. \& Swift, M. J. Agricultural intensification and ecosystem properties. Science 277, 504-509, doi:10.1126/science.277.5325.504 (1997).

12 Fraser, E. et al. Biotechnology or organic? Extensive or intensive? Global or local? A critical review of potential pathways to resolve the global food crisis. Trends in Food Science \& Technology 48, 78-87, doi:10.1016/j.tifs.2015.11.006 (2016).

13 Poore, J. \& Nemecek, T. Reducing food's environmental impacts through producers and consumers. Science 360, 987-992, doi:10.1126/science.aaq0216 (2018).

14 Clark, M., Hill, J. \& Tilman, D. The diet, health, and environment trilemma. Annual Review of Environment and Resources, Vol 43 43, 109-134, doi:10.1146/annurev-environ-102017-025957 (2018). 
15 Gebbers, R. \& Adamchuk, V. I. Precision agriculture and food security. Science 327, 828-831, doi:10.1126/science.1183899 (2010).

16 Stevens, C. J. Nitrogen in the environment. 363, 578-580, doi:10.1126/science.aav8215 \%J Science (2019).

17 Vitousek, P. M. et al. Nutrient imbalances in agricultural development. Science 324, 1519-1520, doi:10.1126/science.1170261 (2009).

18 Cui, Z. et al. Pursuing sustainable productivity with millions of smallholder farmers. Nature 555, 363-366, doi:10.1038/nature25785 (2018).

19 Fischer, J. et al. Should agricultural policies encourage land sparing or wildlife-friendly farming? Front Ecol Environ 6, 382-387, doi:10.1890/070019 (2008).

20 Green, R. E., Cornell, S. J., Scharlemann, J. P. W. \& Balmford, A. Farming and the fate of wild nature. Science 307, 550-555, doi:10.1126/science.1106049 (2005).

21 Ewers, R. M., Scharlemann, J. P. W., Balmford, A. \& Green, R. E. Do increases in agricultural yield spare land for nature? Global Change Bio/ 15, 1716-1726, doi:10.1111/j.1365-2486.2009.01849.x (2009).

22 Lark, T. J., Spawn, S. A., Bougie, M., \& Gibbs, H. K. Cropland expansion in the United States produces marginal yields at high costs to wildlife. Nature Commun 11, 1-11 (2020).

23 Grassini, P., Eskridge, K. M. \& Cassman, K. G. Distinguishing between yield advances and yield plateaus in historical crop production trends. Nat Commun 4, doi:10.1038/ncomms3918 (2013).

24 Ray, D. K., Ramankutty, N., Mueller, N. D., West, P. C. \& Foley, J. A. Recent patterns of crop yield growth and stagnation. Nat Commun 3, doi:10.1038/ncomms2296 (2012).

25 Deutsch, C. A. et al. Increase in crop losses to insect pests in a warming climate. Science 361, 916919, doi:10.1126/science.aat3466 (2018).

26 Robertson, G. P. \& Vitousek, P. M. Nitrogen in agriculture: balancing the cost of an essential resource. Annu Rev Env Resour 34, 97-125, doi:10.1146/annurev.environ.032108.105046 (2009).

27 McCann, K. S. et al. Ecosystem entanglement and the propagation of nutrient-driven instability. Ecology Letters In press (2020).

28 Stevens, C. J., Dise, N. B., Mountford, J. O. \& Gowing, D. J. Impact of nitrogen deposition on the species richness of grasslands. Science 303, 1876-1879, doi:10.1126/science.1094678 (2004).

29 Beketov, M. A., Kefford, B. J., Schafer, R. B. \& Liess, M. Pesticides reduce regional biodiversity of stream invertebrates. P Natl Acad Sci USA 110, 11039-11043, doi:10.1073/pnas.1305618110 (2013). 
30 Alston, J. M. \& Pardey, P. G. Agriculture in the global economy. The Journal of economic perspectives 28, 121-146, doi:10.1257/jep.28.1.121 (2014).

31 Costanza, R. et al. The value of the world's ecosystem services and natural capital. Nature 387, 253-260, doi:10.1038/387253a0 (1997).

32 Shortall, O. K. (2013). "Marginal land" for energy crops: Exploring definitions and embedded assumptions. Energy Policy, 62, 19-27.

33 Salzman, J., Bennett, G., Carroll, N., Goldstein, A. \& Jenkins, M. The global status and trends of Payments for Ecosystem Services. Nat Sustain 1, 136-144, doi:10.1038/s41893-018-0033-0 (2018).

34 United Nations. Transforming our World: The 2030 Agenda for Sustainable Development. (2015). <https://undocs.org/en/A/RES/70/1>.

35 Hungate, B. A. et al. The economic value of grassland species for carbon storage. Science Advances 3, e1601880, doi:10.1126/sciadv.1601880 (2017).

36 Hayami, Y. \& Ruttan, V. W. Agricultural development: an international perspective. Rev. and expanded ed. edn, (Johns Hopkins University Press, 1985).

37 Alston, J. M., Babcock, B. A. \& Pardey, P. G. The Shifting Patterns of Agricultural Production and Productivity Worldwide. (lowa State University Digital Repository, 2010).

38 Perfecto, I., Vandermeer, J. H. \& Wright, A. L. Nature's matrix: linking agriculture, conservation and food sovereignty. (Routledge, 2009).

39 Altieri, M. A. \& Rosset, P. Agroecology and the conversion of large-scale conventional systems to sustainable management. International Journal of environmental studies 50, 165-185 (1996).

40 Cochrane, W.W. 1993. The Development of American Agriculture: A Historical Analysis, 2nd edition. Minneapolis, MN: University of Minnesota Press.

41 Clapp, J. \& Isakson, S. R. Risky returns: The implications of financialization in the food system. Development and Change 49, 437-460 (2018).

42 Pimentel, D. \& Pimentel, M. Food, energy, and society. 3rd edn, (CRC Press, 2007).

43 Pellegrini, P. \& Fernández, R. J. Crop intensification, land use, and on-farm energy-use efficiency during the worldwide spread of the green revolution. Proceedings of the National Academy of Sciences 115, 2335-2340, doi:10.1073/pnas.1717072115 (2018).

44 Morefield, P. E., LeDuc, S. D., Clark, C. M., \& lovanna, R. (2016). Grasslands, wetlands, and agriculture: the fate of land expiring from the Conservation Reserve Program in the Midwestern United States. Environmental Research Letters, 11(9), 094005 
45 Pimentel, D. et al. Food production and the energy crisis. Science 182, 443-449, doi:10.1126/science.182.4111.443 (1973).

46 Gelfand, I. et al. Sustainable bioenergy production from marginal lands in the US Midwest. Nature 493, 514-517, doi:10.1038/nature11811 (2013).

47 Brueckner, J. K. Urban sprawl: diagnosis and remedies. Int Regional Sci Rev 23, 160-171, doi:10.1177/016001700761012710 (2000).

48 Young, A. Is there really spare land? A critique of estimates of available cultivable land in developing countries. Environment, Development and Sustainability 1, 3-18, doi:10.1023/a:1010055012699 (1999).

49 Lambin, E. F. \& Meyfroidt, P. Global land use change, economic globalization, and the looming land scarcity. P Natl Acad Sci USA 108, 3465-3472, doi:10.1073/pnas.1100480108 (2011).

50 Wright, C. K. \& Wimberly, M. C. Recent land use change in the Western Corn Belt threatens grasslands and wetlands. P Natl Acad Sci USA 110, 4134-4139, doi:10.1073/pnas.1215404110 (2013).

51 Gellrich, M., Baur, P., Koch, B. \& Zimmermann, N. E. Agricultural land abandonment and natural forest re-growth in the Swiss mountains: a spatially explicit economic analysis. Agriculture, Ecosystems \& Environment 118, 93-108, doi:10.1016/j.agee.2006.05.001 (2007).

52 Prishchepov, A. V., Müller, D., Dubinin, M., Baumann, M. \& Radeloff, V. C. Determinants of agricultural land abandonment in post-Soviet European Russia. Land use policy 30, 873-884, doi:10.1016/j.landusepol.2012.06.011 (2013).

53 Samson, F. \& Knopf, F. Prairie conservation in North-America. Bioscience 44, 418-421, doi:10.2307/1312365 (1994).

54 Canadian Government. Pan-Canadian framework on clean growth and climate change. (Environment and Climate Change Canada, 2016).

55 Daily, G. C. et al. Ecosystem services in decision making: time to deliver. Front Ecol Environ 7, 2128 (2009).

56 Smith, P. et al. Greenhouse gas mitigation in agriculture. Philosophical transactions. Biological sciences 363, 789-813, doi:10.1098/rstb.2007.2184 (2007).

57 Paustian, K. et al. Climate-smart soils. Nature (London) 532, 49-57, doi:10.1038/nature17174 (2016).

58 Minnesota, C. F. F. M. U. FINPACK User's Manual. (Lulu.com, 2012). 
59 Gramig, B. M., \& Widmar, N. J. Farmer preferences for agricultural soil carbon sequestration schemes. Applied Economic Perspectives and Policy 40 502-521 (2018)

60 USDA. "USDA Announces Support for Farmers Impacted by Unjustified Retaliation and Trade Disruption."Press Releases | USDA (2019).

61 Government of Canada. Agricultural programs and services.

Agricultural programs and services - Agriculture and Agri-Food Canada (AAFC) (2019).

62 World Trade Organization. Domestic support: amber, blue, and green boxes. https://www.wto.org/ (2020).

63 Prokopy, L.S. et al. Adoption of agricultural conservation practices in the United States: evidence from 35 years of quantitative literature." Journal of Soil and Water Conservation 74, 520-534, (2019).

64 Zheng, H. et al. Benefits, costs, and livelihood implications of a regional payment for ecosystem service program. Proceedings of the National Academy of Sciences 110, 16681-16686, doi:10.1073/pnas.1312324110 (2013).

65 Campbell, B. et al. Agriculture production as a major driver of the Earth system exceeding planetary boundaries. Ecol Soc 22, 8, doi:10.5751/ES-09595-220408 (2017).

66 World Economic Forum. The global risks report 2018, 13th edition. (Geneva, Switzerland, 2018).

\section{Figures}



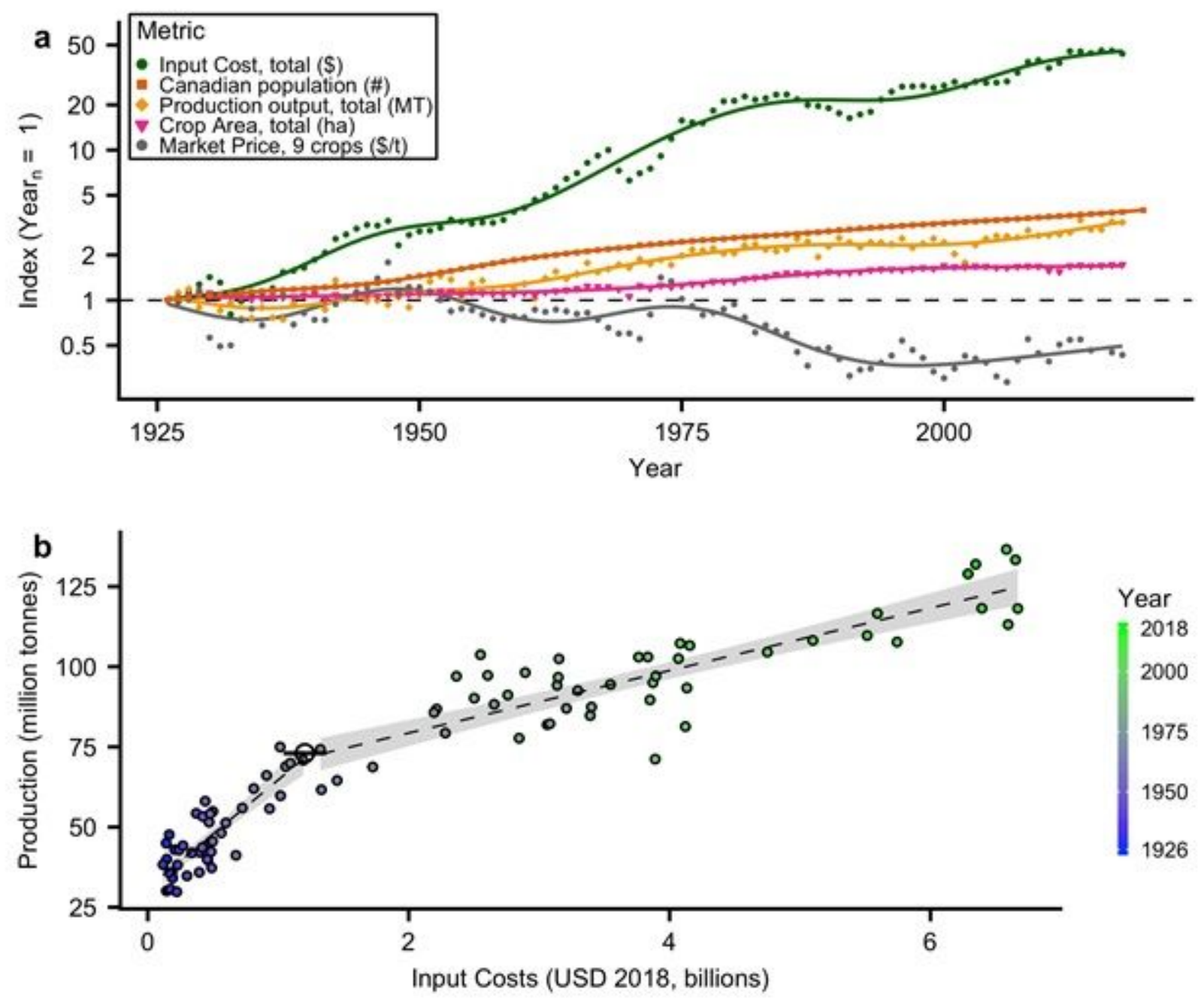

\section{Figure 1}

Observed relationship between agricultural and inflation-adjusted economic factors within Canada. Temporal trends showing a growing gap between agricultural inputs (green circles), human population (orange squares), agricultural productivity outputs (gold diamonds), cropland area (pink inverted triangles), and inflation-adjusted market price (grey circles). In a, agricultural inputs are given as inflationadjusted dollars spent on intensification costs including fertilizers, pesticides, and seed technology (circles). In (a) the response variable is presented as an index where Yearn is the first year that data were available or 1926, whichever is earlier (Supplemental Methods). The dashed black line shows no change from starting conditions (Index $=1$ ). Smoothed lines indicate generalized additive model fits. Panel b shows trend in declining trend of agricultural outputs relative to input cost since 1926 (1926 = blue, $2018=$ green), with the best fit lines and a 95\% confidence interval in grey. 


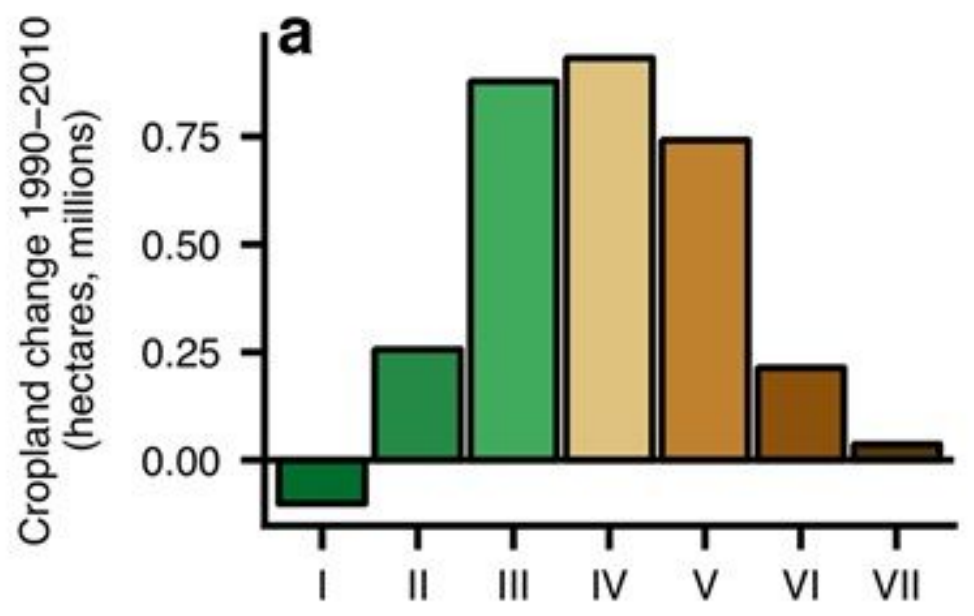

Land class (more fertile $\leftrightarrow$ less fertile)

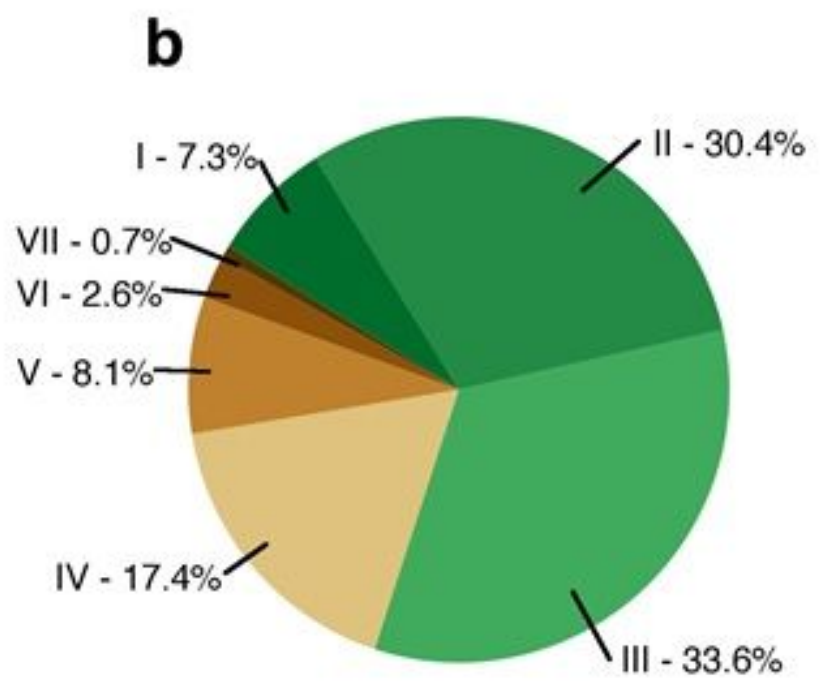

Figure 2

Agricultural land use trends in Canada. Net change in cropland area between 1990 and 2010 corresponding to land class (a, green = suitable for agriculture, brown = marginal lands). The decline of the most arable lands (Class I) can be explained largely by urban expansion into prime agricultural areas. Panel b shows the distribution of cropland in 2010 as it corresponds to land class. 


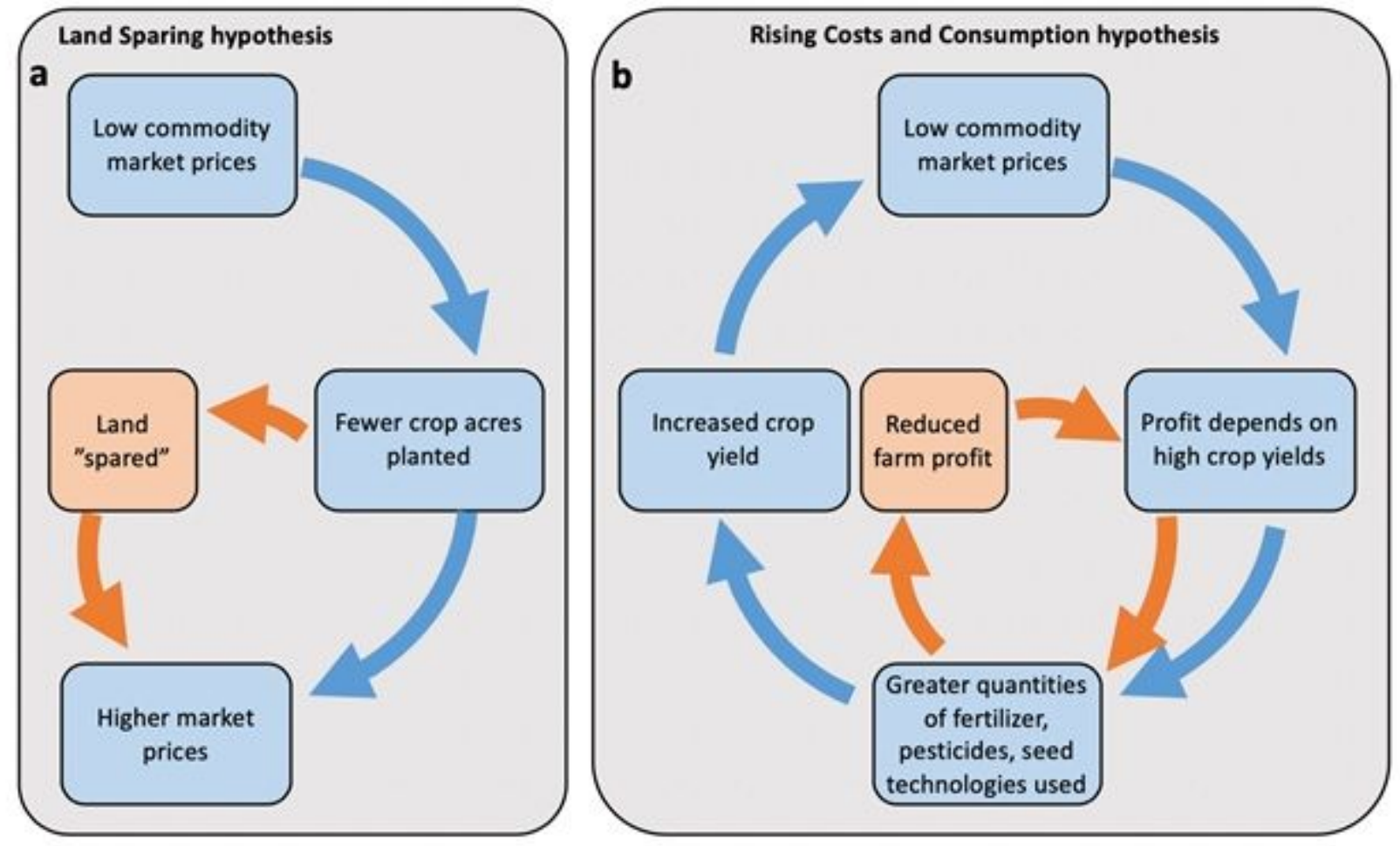

Figure 3

Proposed relationship showing how farm input costs in conjunction with yield (crop output per unit area) and market prices can determine the land consumption trends. If input costs are steady (A), the classic land sparing hypothesis prevails and cultivated land area can decrease. If input costs increase faster than yield gains (B), this can drive an increase in cultivated area by initiating the rising costs and consumption hypothesis. 

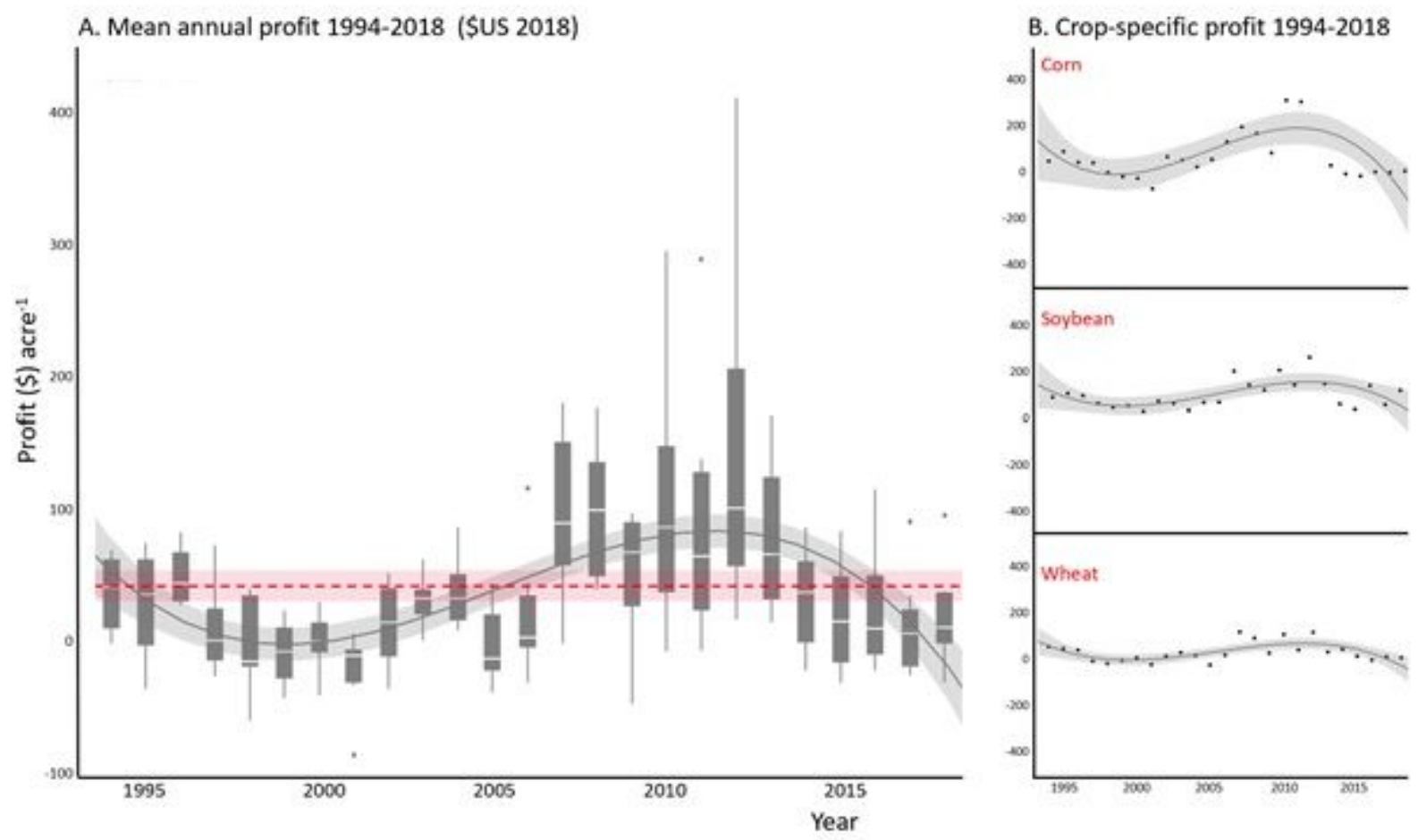

\section{Figure 4}

Inflation-adjusted after-cost revenue "profit" estimates (\$2018 US acre-1) from 1994-2018, for (A) the nine major grain in North American markets, and (B) the same estimates for corn, soybean, and wheat showing how corn prices have been the major driver of after-cost revenue variability in the trends as a whole. These data take into account total farm costs including crop inputs, labor, and transportation (see full list in Table S1) and market price. In (A), the red line shows the mean after-cost revenue estimate, at $\$ 39.2$ (+- $\$ 8$, for the $95 \% \mathrm{Cl}$ ). Not shown are government subsidies, which increases mean revenue estimates to $\$ 53.9$ (+- $\$ 9$ ). The fitted polynomial in (A) shows the best-fit mean after-cost revenue trends $(R 2=0.26 ; F 3,219=25.5, p<0.0001)$, with $(B)$ showing that the fluctuations in these revenues are influenced especially by corn.

\section{Supplementary Files}

This is a list of supplementary files associated with this preprint. Click to download.

- SupplementaryTablesandFigures.pdf 